\title{
3D OBRADA AERO-FOTO SNIMAKA ANAGLIFNOM TEHNOLOGIJOM U FUNKCIJI VIZUELIZACIJE PROSTORA IZVOĐENJA BORBENIH DEJSTAVA
}

\author{
Dragan Vasiljević ${ }^{1}$, Julijana Vasiljević \\ ${ }^{1}$ Generalštab Vojske Srbije \\ ${ }^{2}$ Ministarstvo prosvete, nauke i tehnološkog razvoja Republike Srbije
}

\begin{abstract}
:
Primena informaciono-komunikacionih tehnologija u procesu donošenja odluka predstavlja važan faktor za racionalnu upotrebu resursa. U radu se opisuje primena novih tehnologija procesiranja podataka o prostoru dobijenim aero-foto snimanjem, anaglifna tehnologija, upotreba „open - source“ platformi, prilagođenje standardnim softverskim platformama i korisnički pristup.
\end{abstract}

\author{
Key words: \\ anaglifna tehnologija, \\ aero-foto snimanje, \\ „open - source“ platforme.
}

\section{UVOD}

Ono što razboritim suverenima i dobrim generalima omogućuje da izvrše napad $i$ osvajanja, da postignu ciljeve koje obični ljudi ne mogu, to je prethodno saznanje.

Sun Tzu

Drevna kineska knjiga o vojnoj strategiji autora „Sun $T z u-a$ “ poznata pod nazivom "Umetnost ratovanja“ opisuje važnost „prethodnog saznanja“ za postizanje određenih ciljeva.

Jedna od metoda za postizanje ciljeva je izviđanje prostora koje omogućuje „prethodno saznanje“ o protivniku, fortifikacijskom uređenju i geografskim karakteristikama prostora za izvođenje borbenih dejstava.

\section{KRATKA ISTORIJSKA RETROSPEKTIVA IZVIĐANJA IZ VAZDUHA}

Od nastanka avijacije 1912. godine sve do kraja Prvog svetskog rata, Srbija je u kontinuitetu bila u ratnom okruženju. Izviđanje iz vazduha uvodio je novu dimenziju ratovanja. Prvi izviđački let - izviđanje turskih položaja do visine 2200 metara zabeležen je 29. marta 1913. godine. Naredne godine, tačnije 13. avgusta 1914. godine, srpki piloti sa avionom „blerio“ izvršavali su zadatke izviđanja neprijateljskih mostobrana na Drini i Savi u toku Cerske bitke. Radi izviđanja područija budućih operacija u Sremu je vrlo brzo formirano Aeroplansko odeljenje Šumadijske divizije, koje je izvršavalo izviđačke zadatke za potrebe Prve armije ${ }^{1}$.

Januara 1975. godine u naoružanje JNA su uvedeni avini MiG-21MF sa NATO oznakom „Fishbed-J“. Tokom 1983 godine takva četiri aviona su prerađena u izviđače. Izviđačka oprema za ovu vrstu avijacije bila je „LORAP KA-112A - Long range aerial panoramic photographic system". Ovaj sistem je označio prekretnicu u opremanju izviđačke avijacije. Srce ovog sistema činila je panoramska kamera "KA-112A“, čija je namena koso snimanje teritorije susednih država po visini od 10.000 metara i po bočnoj dubini do 110 kilometara [1].

\section{SADAŠNJE STANJE}

Ministarstvu odbrane Republike Srbije odlučilo je da za potrebe fotogrametrijskog snimanja nabavi nov avion „Piper Seneca V”. Osnovu sistema za fotogrametrijsko snimanje čini sistem „Leica ADS80“ koja predstavlja vazduhoplovni digitalni senzorski sistem visokih performansi, zajedno sa softverom „Leica XPro“ predstavlja kompletnu tehnološku celinu za aero-foto snimanje i obradu podataka. Sada, se koriste štamane karte različitih razmera bez digitalizovane baze podataka.

1 Više o razvoju srpske avijacije možete saznati na sajtu „Istorija aviona" na adrsi: http://www.znanje.org/i/i26/06iv01/06iv0107/ Web\%20prezentacija/index.htm 


\section{ZNAČAJ IZVIĐANJA U PROCESU DONOŠENJA VOJNIH ODLUKA}

Izviđanje je aktivnost koju u sklopu obaveštajnog obezbeđenja planiraju, organizuju i sprovode oružane snage radi prikupljanja podataka o neprijatelju, prostoru borbenih dejstava i meteorološkim uslovima. Organnizuje se i sprovodi neprekidno u svim oblicima oružane borbe i u svim vidovima borbenih dejstava. Izviđati se može sa zemlje, vodenih površina i iz vazduha.

\section{IZVIĐANJE IZ VAZDUHA}

Izviđanje iz vazduha je svako prikupljanje podataka izvršeno u toku leta. Vrši se vizuelno i tehničkim sredstvima visoke tehnologije. Osnovna komponenta za izviđanje iz vazduha je izviđačka avijacija, kao i ostale vrste vazduhoplova. Inače, sve posade pri izvršenju borbenih zadataka vrše i izviđanje iz vazduha, neprekidno u sklopu dodeljenog zadatka.

Svako izviđanje iz vazduha vrši se za potrebe komandovanja Kopnene vojske i Vazduhoplovstva, a karakteriše ga:

- mogućnost brzog prenosenja težišta u izboru izviđanja,

- raznovrsnost podataka koji se mogu prikupiti,

- velika tačnost podataka i

- zavisnost od meteo situacije, karaktera zemljišta, doba dana i noći i sposobnosti neprijateljske protivvazduhoplovne odbrane.

Opšti zadaci izviđanja iz vazduha su: izviđanje neprijatelja, izviđanje zemljišta, izviđanje vremena, kontrola rezultata borbenih dejstava ispoljenih tokom operacije i kontrola maskiranja sopstvenih jedinica.

\section{AERO-FOTO IZVIĐANJE}

Ova vrsta izviđanja podrazumeva prikupljanje podataka aero-foto snimanjem, obradu i dešifrovanje aerofoto snimaka. Primenjuje se prvenstveno za izvidjanje stacionarnih i manje pokretnih objekata. Ukoliko dozvoljavaju uslovi, pri aero-foto izvidjanju vrši se i vizuelno osmatranje objekata koji se snimaju radi bržeg i tačnijeg dešifrovanja aero-foto snimaka. Može se snimati danju i noću, s tim što se noću koriste i sredstva za osvetljavanje objekta snimanja. Snimanje karakteriše:

- velika tačnost i dokumentovanost podataka,

- mogućnost izviđanja sa velikih visina van efikasnog dometa neprijateljske protivvazduhoplovne odbrane,

- mogućnost istovremenog korišćenja kopija aerofoto snimaka od strane više korisnika,

- zavisnost od raspoloživog vremena potrebnog za obradu i desifrovanje snimaka i

- zavisnost od meteo uslova koji mogu delimično, ili u potpunosti da onemoguće aero-foto snimanje.

Aero-foto snimanje, u odnosu na položaj optičke ose objektiva kamere, može biti vertikalno i koso. Razmera aero-foto snimaka se određuje prema nameni korišćenja, a može biti:

- vrlo krupna, do 1:5000 za detaljno izučavanje svih elemenata neprijateljske odbrane, kao i raznih objekata za koje se traže što preczniji podaci o njihovoj konstrukciji, izgledu i sl.

- Krupna, od 1:5000 do 1:12000 je osnovna razmera za otkrivanje većine objekata i stanja kod neprijatelja.

- Srednja, od 1:12000 do 1:20000, a sitna razmera preko 1:20000 kotisti se za iznalaženje terena za aerodrome i rejone za iskrcavanje padobranskih desanata, kao i za razne druge potrebe.

Aero-foto maršrutom snimaju se uski a dugački objekti (saobraćajnice, reke i sl.) [2].

Aero-foto celinom se snimaju veći rejoni i objekti koji ne mogu da se obuhvate jednom foto maršrutom. Obradom aero-foto snimaka obezbeđuje je vizuelizacija prostora izvođenja borbenih dejstava, što donosiocima odluke može biti od ključnog značaja za uspeh misije. Pored vojnog aspekta vizuelizacija prostora može biti od velikog značaja prilikom definisanja potrebnih snaga i sredstava za rešavanje akcidentnih kriza ili pomoći civilima u slučaju elementarnih nepogoda ili drugih nesreća [3].

\section{ANAGLIFNA TEHNOLOGIJA U FUNKCIJI 3D PRIKAZA}

Anaglifski metod u 3D obradi slika je verovatno najpoznatiji i najstariji način „oblikovanja“ treće dimenzije. Metoda se sastoji u predstavljanje dve slike istovremeno pri čemu jedna preklapa drugu, uz dodavanje dve različite boje - crvene i zeleno/plave za slojeve.

Da bi se svaka slika gledala drugim okom nose se specijalne naočare, sa obojenim filterima koji svakom oku omogućavaju da vidi odgovarajući sloj (sliku), pri čemu se druga boja vidi kao crna. To su popularne „crveno zeleno/ plave” naočare. Dubina prikaza, bilo da se radi o statičnoj ili pokretnoj slici postiže se razdvajanjem dva sloja. Pri tome je centralni objekat u fokusu, dok su pozadina, kao i deo ispred centralnog objekta prikazani u kombinaciji razdvojenih slojeva [4].

Razdvajanje slojeva kod dela ispred centralnog objekta i onoga kod pozadine su suprotni, kako bi se dobila iluzija da je jedan deo bliži, a drugi dalji u odnosu na fokusirani objekat.

Najveća prednost ove tehnologije jeste ta što je njena implementacija vrlo pristupačna, dok je oprema potrebna za gledanje još jeftinija. Upotrebom „open - source“ aplikacije „Stereo Photo Maker" snimci prikazani na slici 7. i slici 8. mogu se obraditi anaglifnom metodom na sledeći način:

1. Neophodno je obezbediti levi i desni snimak (avio snimak, snimak fotoaparatom, ...). Nakon toga, snimci moraju da se preimenuju, tako da im se doda sufiks „L“ ili „R“, u zavisnosti da li se radi o levom ili desnom snimku, na primer: - Snimak_L.tif Snimak_R.tif 


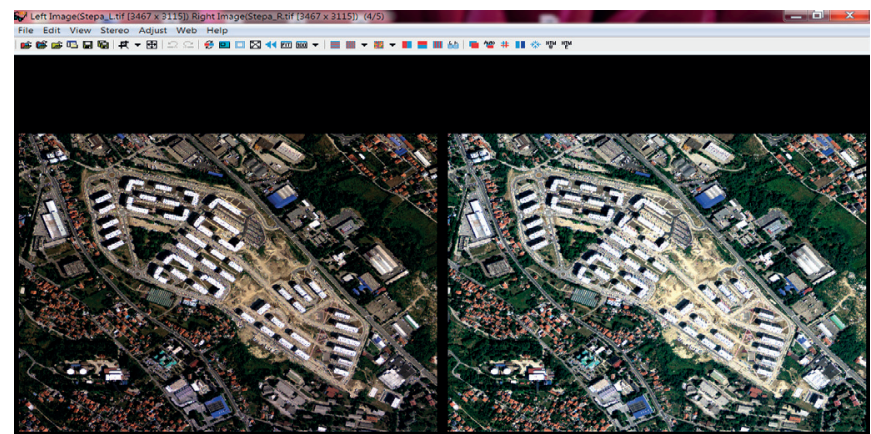

Sl. 1. Prikaz definisanih snimaka

Slike mogu biti u bilo kom rasterskom formatu (tiff, bmp, jpg, gif, png, ...). Na slici 1. dat je prikaz definisanih snimaka sa određenim sufiksom L.tif i R.tif i njihov unos u „open - source“ aplikaciju „Stereo Photo Maker".

2. Nakon toga, opcija Open Left/Right Images... Otvara se prozor pomoću kojeg se u program učitava levi i desni snimak.

3. U tećem koraku otvaramo opciju „Adjust/Auto Alignment“, zatim opcija „Adjust/Easy Adjustment".

4. Na kraju, opcija „Stereo / Color Anaglyph color(red/cyan)“. Kao rezultat, dobija se slika obrađena anaglifnom metodom, prikaz 3D slike naselja „Stepa Stepanovićc u Beogradu dat je na slici 2.

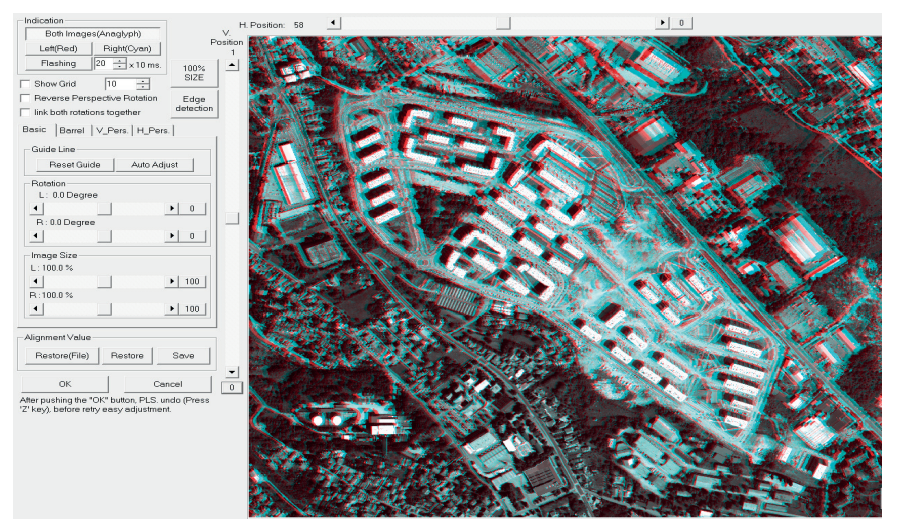

Sl.2. Prikaz 3D slike naselja „Stepa Stepanovic““ u Beogradu

Pre ubacivanja slika u program, neophodno je izvršiti njihovo izjednačavanje „Brightness/Contrast i Color" $\mathrm{u}$, npr., „Photoshop-u“. Takođe, leva i desna slika treba da budu istih dimenzija. Veoma je važno uraditi korak 1, odnosno, preimenovanje levog i desnog snimka. Takođe korišćenjem „open - source“ aplikacije „Stereo Photo Maker" moguće je pripremiti snimak za mobilne aplikacije ili za prikaz na „web“ stranicama. Druga „open source“ aplikacija za 3D prikaz, „open - source“ aplikacija za 3D prikaz, koja je po postupku kreiranja 3D slika vrlo slična aplikaciji "Stereo Photo Maker“, ali sa poboljšanim karakteristikama u odnosu na „Free 3D Photo Maker“. Izgled slike naselja „Stepa Stepanović" dobijen anaglifnom metodom prikazana je na slici 3.

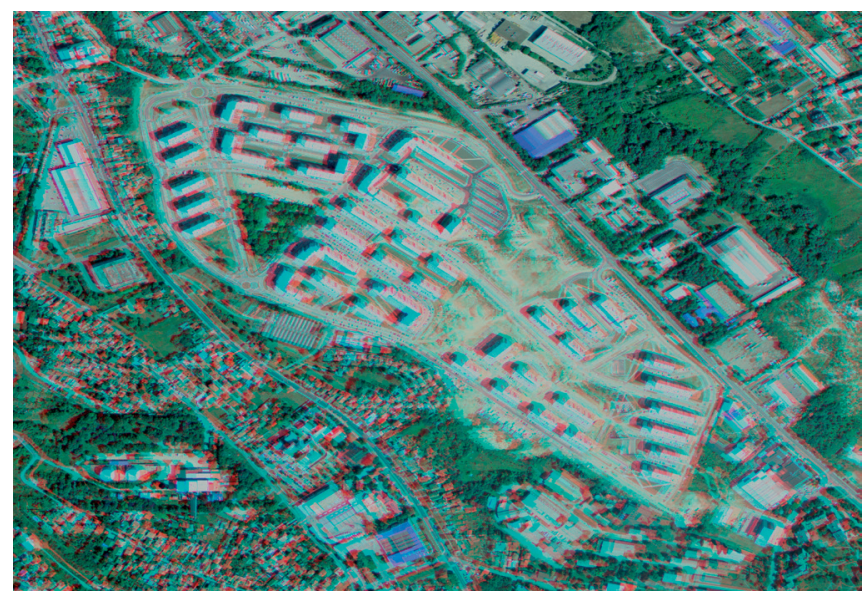

Sl. 3. 3D prikaz pomoću „Free 3D Photo Maker-a“

\section{ANALIZA POSTOJEĆEG STANJA}

Trenutno je $\mathrm{u}$ toku proces uvođenja $\mathrm{u}$ operativnu upotrebu aviona „Piper Seneca V”, koji bi integrisao senzorski sistem „Leica ADS80“, čime bi se zaokružio postupak operacionalizacije zadataka vezanih za aero-foto izviđanje. Upotrebom anaglifne tehnologije, korišćenjem i drugih opisanih „open - source“ aplikacija već sada smo u mogućnosti da uspešno izvršimo vizuelizaciju prostora izvođenja borbenih dejstava.

\section{UOČENI PROBLEMI}

Moguće je obrađivati aero-foto snimke primenom pogodne „open - source“ ili neke druge komercijalne aplikacije za obradu aero-foto snimaka anaglifnom metodom, što zahteva dodatno vreme u procesu donošenja odluka.

Za sada, ne postoji izrađen informacioni sistem u čijoj bazi podataka bi bili smešteni aero-foto snimci razvrstani po oblastima.

Ne postoji izrađen informacioni sistem $\mathrm{u}$ čijoj bazi podataka bi bili smešteni već obrađeni 3D snimci terena.

Distribucija obrađenih 3D slika u komandno-informacionom sistemu može dovesti do „smanjenja“ protoka informacija $\mathrm{i}$

Digitalizacija i vizuelizacija prostora izvođenja borbenih dejstava je u stvari proces prenošenja informacija oprostoru u bližem realnom vremenu između borbenih elemenata, da bi se omogućila podjednaka svest o taktičkoj situaciji. Ostvarenje napred navedenog podrazumeva integraciju 3D slika prostora sa snagama i sredstvima na terenu, što podrazumeva razvoj novog informacionog sistema.

\section{PREDLOG REŠENJA}

Jedno od mogućih rešenja je razvoj integrisanih informacionih sistema (mobilna oprema, sistemi za nadzor, mobilna telefonija, satelitske komunikacije i dr.), koji bi bio direktno uvezan sa zemaljskim terminalima, tehnologije za emitovanje, faksimili, video signal, prikazi u boji, sistem za globalno pozicioniranje (GPS), digitalne 
topografske karte i baze podataka, na taj način postaju dostupni neposrednim izvršiocima. Ovakva tehnologija bi obezbedila mogućnost donosiocu odluke i izvršiocima da dobijaju i razmenjuju tačne podatke o situaciji u prostoru izvođenja borbenih i neborbenih dejstava, što opet omogućava reakciju u realnom vremenu [5].

Upotpunjavanje slike o stanju u prostoru izvođenja borbenih i neborbenih dejstava uz primenu anaglifne metode obrade snimaka se postiže automatskim ažuriranjem grafičkih prikaza na topografskoj karti i lejera, čime se potčinjenim sastavima pružaju informacije o stanju sopstvenih i neprijateljskih jedinica.

Opšta slika u realnom vremenu uz integraciju 3D slika omogućava donosiocu odluka i izvršiocima da na osnovu informacija donesu pravovremenu odluku, bolje komanduju svojim snagama, sinhronizuju dejstva i postignute efekte i izvrše misiju uz minimalne gubitke.

Komandno-informacioni sistem će u budućnosti osigurati veliku tehnološku prednost donosiocima odluka i izvršiocima. Sistemi za automatsku digitalnu razmenu informacija između učesnika u prostoru izvođenja borbenih dejstava trebalo bi da omoguće: relativno precizno određivanje položaja, identifikaciju prijatelj-neprijatelj, pravac, azimut, određivanje ciljeva i podršku. Drugi informacioni sistemi će moći da razmenjuju baze podataka u računarskoj mreži i pomoći u izvršavanju zadataka. Tehnologija koja se razvija će olakšati unos, korišćenje i razmenu podataka u terenskim uslovima, što omogućuju nove „web“ zasnovane tehnologije.

\section{PRIKAZ „WEB“ ZASNOVANE TEHNOLOGIJE U ARMIJI SAD}

Na slici 4. dat je prikaz inteoperabilnosti sistema i procesa gde se vidi jasna povezanost između procesa kontrole i komandovanja sa „geoweb“ aplikacijom koja u sebi integriše geo. - „web“ informacioni sistem sa podacima dobijenim od senzora [6]. Osnovna funkcija ovakvog sistema je korišćenje i razmena podataka u realnom vremenu [7].

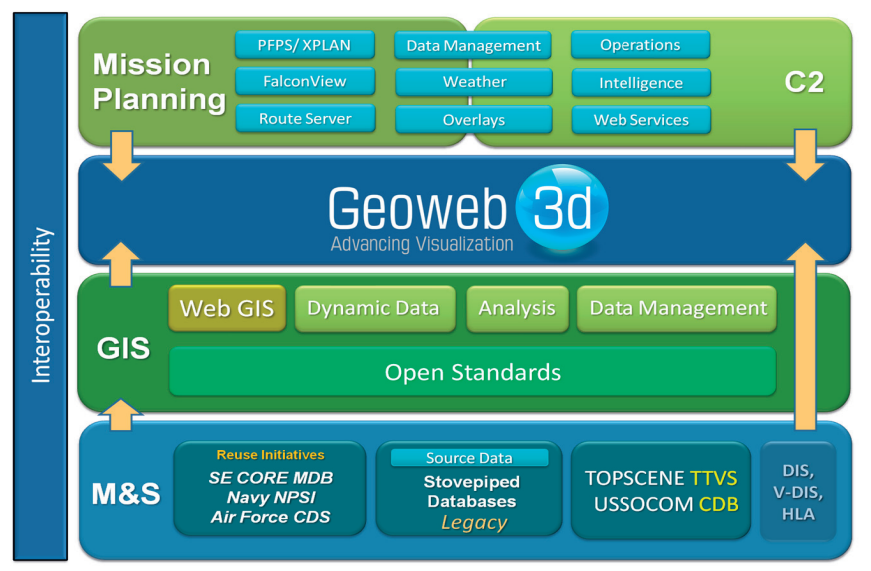

Sl.4. prikaz „web“ zasnovane tehnologije u armiji SAD

\section{LITERATURA}

[1] Memon, G. (1998): Izvidjacki avioni za vodjenje elektronskog rata. Vojnotehnički institut u Beogradu, Vojni glasnik, Beograd.

[2] Borisov A. Mirko, Banković D. Radoje (2011): Primena GIS sa aspekta multifunkcionalnosti. Vojska Srbije, Vojnogeografski institut, Beograd.

[3] Ponjavić, M. (2011): Osnovi geoinformacija. Građevinski fakultet Univerziteta u Sarajevu, Sarajevo.

[4] Keresteš K. (2002): Making The Anaglyph Map. Journal of the Association of Surveyors of Slovenia, Ljubljana.

[5] Lovett A., Appleton K. (2008): GIS for Environmental Decision - Making, CRC Press, Boca Raton, London, New York.

[6] Information Dominance for Army XXI: Battlefield Visualization http://www.fas.org/irp/agency/army/mipb/19971/jones.htm .

[7] Geoweb3d http://www.geoweb3d.com/products/ desktop/3d-views/

\section{D RENDERING AERO PHOTO IMAGE USING ANAGLYPH TECHNOLOGY FOR VISUALIZATION OF COMBAT OPERATIONS SPACE}

\section{Abstract:}

The use of ICT in the decision-making process is an important factor for the economical use of resources. This paper describes the application of new technology of processing spatial data obtained framing recording, anaglyph technology, the use of "open - source" platform, suiting standard software platforms and user access.

\section{Key words:}

anaglyph technology, aero - photo shoot, "open - source " platform. 